\title{
Formalization of management control systems: a study of companies in Croatia
}

\author{
Ivana Dropulić ${ }^{1, *}$ and Andrijana Rogošić ${ }^{2}$ \\ ${ }^{1}$ Accounting Department, Faculty of Economics, University of Split \\ Cvite Fiskovića 5, HR-21000 Split, Croatia \\ E-mail: 〈ivana.dropulic@efst.hr〉 \\ 2 Accounting Department, Faculty of Economics, University of Split \\ Cvite Fiskovića 5, HR-21000 Split, Croatia \\ E-mail: 〈andrijana.rogosic@efst.hr〉
}

\begin{abstract}
This study seeks to explain management control systems (MCS) design as a package of controls within a Croatian context. MCS was conceptualized in terms of four dimensions: cybernetic, reward and compensation, administrative and cultural controls to form a composite measure of MCS. The strength of the typology lies in the broad scope of the controls in MCS as a package rather than the depth of its discussion of individual systems. This is one of few research studies conducted in the field of MCS in Croatia. Empirical research is based on the data collected from 124 companies in Croatia using a post questionnaire. The final results indicate that companies in Croatia most frequently use more formalized MCS tested using confirmatory factor analysis. This research confirms the multidimensional nature of MCS.
\end{abstract}

Key words: management control systems, strategic management accounting, formalization, confirmatory factor analysis

Received: November 12, 2013; accepted: March 10, 2014; available online: March 20, 2014

\section{Introduction}

This paper examines management control systems (MCS) as a package [1], [4], [6], [9], [12], [14], [16], [18] by paying particular attention to the couplings among cybernetic, reward and compensation, administrative and cultural controls. The purpose of this paper is to add to the limited body of knowledge of the design of MCS because what really makes MCS is not precisely defined. Further research is needed to examine the concept of MCS as a package of controls. MCS supports the creativity of employees, improving the operational efficiency and competitiveness of enterprises. However, there is no universally best MCS that applies to all situations in any organization, much less all organizations [15]. To improve the process of research on this subject, it is necessary to determine influential variables that affect the MCS design. This research examines issues related to the purpose of MCS and the elements of MCS with no attempt to assess the meaning and measurement of influential factors and their relationship with different elements of MCS.

${ }^{*}$ Corresponding author. 
The paper is organized as follows. The next section provides a literature review of the definitions of MCS and previous research. Section 3 outlines the research methodology while the results are discussed in Section 4. Finally, Section 5 summarizes empirical findings and provides a brief outlook for further research.

\section{Definition of management control systems and previous research}

MCS have been defined and conceptualized in many different ways. Some of those definitions overlap, but others are quite different [6], [9], [14]. Anthony [5] defines management control as ...

"... the process by which managers ensure that resources are obtained and used effectively and efficiently in the accomplishment of the organization's objectives".

The current trend in management control research is to combine the use of formal and informal systems, because it is considered that through the sole use of formal systems it is impossible to control relevant variables for an organization to achieve its objectives [8]. According to Malmi and Brown [14], management controls include all devices and systems managers use to ensure that the behaviors and decisions of their employees are consistent with the organization's objectives and strategies. Management control systems (MCS) embody the techniques and mechanisms which companies employ to pursue objectives, accomplish goals and successfully pursue strategies [10].

The concept of MCS that represents a combination of various cybernetic, reward and compensation, administrative and cultural controls with related techniques is used in this research. This concept is based on research of Malmi and Brown [14]. They suggest a new typology for MCS structured as a package of controls. There are four basic cybernetic systems that have been identified in MCS research that are considered in this research: budgets, financial measures, non-financial measures and hybrids that contain both financial and non-financial measures [14]. Reward and compensation controls focus on motivating and increasing the performance of individuals and groups within organizations by achieving congruence between their goals and those of the organization [7]. This research is concerned with three attributes of reward and compensation controls: benchmarking for comparison, bonus determination criteria and performance evaluation criteria [3]. Three groups of controls are observed for administrative controls: organization design and structure, governance structures within the company and the procedures and policies [14]. The three aspects of cultural control, i.e. value-based controls, symbol-based controls and clan controls [14], are also considered. 


\section{Methodology of research}

\subsection{Research hypothesis}

Companies are expected to exercise control along a continuum for each of the MCS dimensions. Drawing on definitions and descriptions of controls used in prior studies [6], it is suggested that one end of the control continuum is more formalized controls meaning more use of cybernetic controls (except non-financial measures), more use of administrative and cultural controls and more use of reward and compensation based on internal standards, objective criteria and short-term measures. Accordingly, the other end of the continuum is the less formalized controls meaning less use of cybernetic (except non-financial measures), less use of administrative and cultural controls and more use of reward and compensation based on external standards, subjective criteria and long-term measures.

In literature, MCS are usually explained in the context of strategic management accounting. The accounting perspective had a strong impact on MCS development. Since there is no previous research on multidimensional aspects of MCS in Croatia, the hypothesis development is based on papers published in the field of accounting. The study of Ramljak and Rogošić [17] shows that most of the large companies in Croatia have implemented at least one of strategic management accounting techniques. Dropulić and Pervan [11] revealed that almost every company in Croatia has budgetary control. Since related studies [11], [17] suggest the strong use of cybernetic controls (mostly instruments of management accounting), it can be assumed that:

\section{H1: Companies in Croatia have more formalized management control systems design}

The above hypothesis will be evaluated by descriptive statistics, chi-square test and confirmatory factor analysis on the Croatian dataset.

\subsection{Description of the sample}

The research was based on data collected by using the post questionnaires sent to financial managers of 498 randomly selected companies in Croatia with at least 100 employees. It is expected that small companies are less likely to have a real need for complex management control systems [13]. A total of 124 useable questionnaires were received (a response rate of 25\%). For a field survey involving a complex questionnaire, such as in this research, a response rate of about $20-22 \%$ is usually considered very good [19]. Thus, it was decided that the response rate reached was adequate for conducting statistical analyses.

\subsection{Description and measurement of variables}

The concept of MCS that represents a combination of various cybernetic, reward and compensation, administrative and cultural controls is the basis of this study. Budgets, financial measures, non-financial measures and hybrid measures were used for measuring cybernetic controls. The use of budgets was measured based on the 
responses on 13 questions. The use of financial, non-financial and hybrid measures is analyzed based on the responses on 12 questions. Using a five-point Likert scale, ranging from strongly disagree to strongly agree, respondents were asked to indicate the extent to which they perceived 25 items relating to cybernetic controls were used in their organizations.

Three questions which measure the managerial evaluation and reward system were used for measuring reward and compensation controls. The first question deals with benchmarking for comparison of managerial performance. Respondents were asked, using a five-point semantic scale, to determine the degree of emphasis given to internal standards relative to external standards when evaluating managerial performance. The second question focuses on the criteria used for bonus determination. Respondents were asked to indicate the extent to which bonus remuneration is determined by objective criteria compared to subjective criteria. A five-point semantic differential scale ranging from an exclusive emphasis on objective criteria to an exclusive emphasis to subjective criteria, with the middle point indicating that the "same emphasis is given to both criteria". The third question measures the relative emphasis that is given to short-term financial criteria compared to long-term nonfinancial criteria when evaluating managerial performance. A five-point scale ranging from "exclusive emphasis on short term criteria" to "exclusive emphasis on long-term criteria" with the middle point indicating the "same emphasis is given to both criteria" [3].

Two dimensions of organizational structure, centralization and formalization, were used for measuring administrative controls. Centralization and formalization [3] were measured based on the answers on 9 questions. Respondents were asked, on a five-point Likert scale ranging from 1 (strongly disagree) to 5 (strongly agree) to express a degree of agreement or disagreement with the specified statement. Value based controls, symbol based controls and clan controls were used for cultural controls which impact employee behavior. The respondents for each of the 3 questions circled the appropriate number from 1 (strongly disagree) to 5 (strongly agree) corresponding a degree of agreement or disagreement with the specified statement.

\section{Research results}

Table 1 presents the statistics on companies in terms of size. This study measures company's size according to the criteria of Accounting Act [20], which classifies companies as small, medium and large according to the following criteria: total assets, revenues and average number of employees during the year. In a sample of 124 companies, there are $72(58.10 \%)$ medium size, $35(28.20 \%)$ large and 16 $(12.90 \%)$ small companies.

\begin{tabular}{|l|c|c|c|c|c|}
\hline $\begin{array}{l}\text { Size of } \\
\text { company }\end{array}$ & Small & Medium & Large & Missing data & Total \\
\hline $\mathrm{N}$ & $16(12.9 \%)$ & $72(58.1 \%)$ & $35(28.2 \%)$ & $1(0.8 \%)$ & $124(100 \%)$ \\
\hline
\end{tabular}

Table 1: Profile of the companies

Companies are classified according to the criteria of the National Classification of 
Activities 2007-NCA 2007 [21] in different industries. NCA classifies entrepreneurs in 21 different categories. $39.5 \%$ of companies in the sample are manufacturing companies, $14.5 \%$ are wholesale and retail trade; repair of motor vehicles and motorcycles companies and $9.7 \%$ are construction companies.

The first component of MCS are cultural controls (value based controls, symbol based controls and clan controls). Administrative controls are the second component of MCS (centralization and formalization). Cybernetic controls are the third component of MCS (budgets, financial measures, non-financial measures and hybrid measures) and the fourth component of MCS are reward and compensation controls (internal vs. external standards, objective vs. subjective criteria and short-term vs. long-term measures). Descriptive statistics for four controls of MCS ( $1=$ cultural controls, $2=$ administrative controls, $3=$ cybernetic controls and $4=$ reward and compensation controls) are presented in Table 2 and descriptive statistics for all components of cultural, administrative, cybernetic and reward and compensation controls are presented in Table 3.

\begin{tabular}{|l|c|c|c|c|}
\hline Four MCS controls & 1 & 2 & 3 & 4 \\
\hline N & 124 & 124 & 124 & 118 \\
\hline Missing & 0 & 0 & 0 & 6 \\
\hline Mean & 3.2379 & 4.1542 & 3.3281 & 3.4195 \\
\hline Std. deviation & 0.89921 & 0.71574 & 0.45263 & 0.62806 \\
\hline
\end{tabular}

Table 2: Descriptive statistics for $M C S$

\begin{tabular}{|c|c|c|c|c|c|}
\hline MCS & Components of controls & $\mathrm{N}$ & Missing & Mean & Std. dev. \\
\hline \multirow{2}{*}{1} & Value based controls & 124 & 0 & 3.5403 & 1.03121 \\
& Symbol based controls & 123 & 1 & 3.1220 & 1.09832 \\
& Clan controls & 122 & 2 & 3.0410 & 1.20191 \\
\hline 2 & Centralization & 124 & 0 & 4.2677 & 0.82083 \\
& Formalization & 123 & 1 & 3.9702 & 0.79015 \\
\hline 3 & Budgets & 122 & 2 & 3.6516 & 0.76437 \\
& Financial measures & 124 & 0 & 4.1653 & 0.80767 \\
& Non-financial measures & 123 & 1 & 3.6591 & 0.74657 \\
& Hybrid measures & 113 & 11 & 2.7876 & 1.25678 \\
\hline \multirow{2}{*}{4} & Internal vs. external standards & 118 & 6 & 3.4915 & 0.88430 \\
& Objective vs. subjective criteria & 110 & 14 & 3.3818 & 1.07500 \\
& Short-term vs. long-term measures & 108 & 16 & 3.3981 & 0.88539 \\
\hline
\end{tabular}

Table 3: Descriptive statistics for all components of MCS

Although the MCS framework developed in this study was based on theoretical foundations, no study has tested whether the items, when grouped together, measure the same underlying concept. Confirmatory factor analysis (CFA) was selected to form the MCS variable. It is common to display confirmatory factor models as path diagrams in which squares represent observed variables and circles represent latent variables. Figure 1 has one latent variable MCS (in the circle) that is manifested by four observed variables: cultural, administrative, cybernetic and reward and compe- 
nsation controls (in squares). Single-headed arrows are used to imply a direction of the assumed causal influence. The latent variable causes the observed variables, as shown by single-headed arrows pointing away from the circles and towards the manifest variables [2]. In the research model, there are four manifest variables obtained as the arithmetic mean of a number of questions in the questionnaire. All data were previously normalized by min-max normalization to achieve comparability of the ordinal scale of 1 to 5 . The normalization procedure results in values from 0 to 1 or from $0 \%$ to $100 \%$, which is ultimately more easily to interpret. Factor loadings present the effect of MCS on cultural, administrative, cybernetic and reward and compensation controls. All factor loadings were estimated using maximum likelihood and ranged from 0.23 to 0.58 . In addition to each manifest variable the squared value of the multiple correlation coefficient was displayed measuring the proportion of the variance explained. The percentage of variance explained by the manifest variables varies from $5 \%$ to $34 \%$. The remaining variance is unexplained and attributed to the action component of random errors and unknown factors (residuals). Variables representing the residuals are presented by markings e1, e2, e3 and e4.

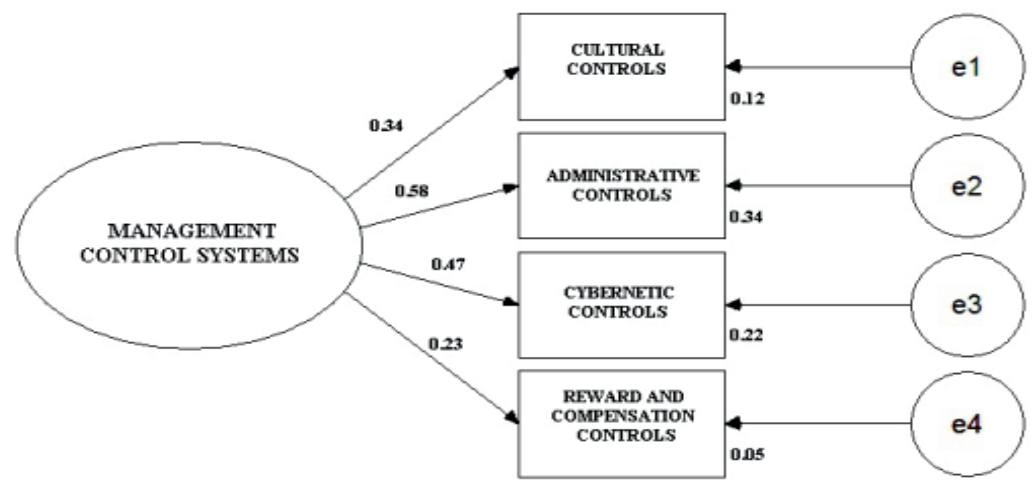

Figure 1: Management control systems according to CFA

A non-standardized value of the estimated parameters, their standard errors, test size and p-value are presented in Table 4.

\begin{tabular}{|l|c|c|c|c|}
\hline & Estimate & S.E. & C.R. & P \\
\hline Cultural controls & 1.000 & & & \\
\hline Administrative controls & 1.867 & 0.740 & 2.523 & 0.033 \\
\hline Cybernetic controls & 0.789 & 0.343 & 2.300 & 0.041 \\
\hline Reward and compensation controls & 0.573 & 0.326 & 1.758 & 0.077 \\
\hline
\end{tabular}

Table 4: Non-standardized value of the estimated parameters

One variable in the measurement model is necessary to declare the carrier, and it gets a priori multiplier 1, while the other multipliers scaled to it (it is "cultural controls" for the measurement model of management control systems). Two of 
the estimated parameters are statistically significant at a significance level of $5 \%$, while the one is significant at a significance level of $10 \%$. Standardized parameters, constant members and variance are presented in Tables 5, 6 and 7, respectively.

\begin{tabular}{|l|c|}
\hline & Estimate \\
\hline Cultural controls & 0.341 \\
\hline Administrative controls & 0.584 \\
\hline Cybernetic controls & 0.467 \\
\hline Reward and compensation controls & 0.231 \\
\hline
\end{tabular}

Table 5: Standardized value of the estimated parameters

\begin{tabular}{|l|c|c|c|c|}
\hline & Estimate & S.E. & C.R. & P \\
\hline Cultural controls & 3.238 & 0.081 & 40.090 & $* * *$ \\
\hline Administrative controls & 4.155 & 0.064 & 64.589 & $* * *$ \\
\hline Cybernetic controls & 3.328 & 0.041 & 81.941 & $* * *$ \\
\hline Reward and compensation controls & 3.422 & 0.058 & 59.262 & $* * *$ \\
\hline \multicolumn{2}{|l|}{${ }^{* * *} p \approx 0.000$}
\end{tabular}

Table 6: Value of the estimated constant parameters

\begin{tabular}{|l|c|c|c|c|}
\hline & Estimate & S.E. & C.R. & P \\
\hline F1 & 0.193 & 0.073 & 2.644 & 0.029 \\
\hline e1 & 0.709 & 0.106 & 6.691 & $* * *$ \\
\hline e2 & 0.335 & 0.103 & 3.264 & 0.001 \\
\hline e3 & 0.159 & 0.032 & 5.037 & $* * *$ \\
\hline e4 & 0.370 & 0.051 & 7.196 & $* * *$ \\
\hline
\end{tabular}

Table 7: Value of the estimated variance

Thus, it can be concluded that all estimated parameters, including constant parameters and variance, are statistically significant. Based on standardized coefficients, 0.584 is the highest value which means that administrative controls are major contributors to the measurement of management control systems and the direction of its impact is positive and statistically significant. In addition, the percentage of variance explanation of this indicator is $34 \%$. A large class of omnibus tests exists for assessing how well the model matches the observed data. Chi-square $\left(\chi^{2}\right)$ is a classic goodness-of-fit measure to determine the overall model fit. The corresponding p-value is greater than $5 \%$, which confirms that the model is adequately specified and statistically significant (Table 8).

\begin{tabular}{|l|c|c|c|c|c|}
\hline & Number of parameters & $\chi^{2}$ & df & p-value & $\chi^{2} / \mathrm{df}$ \\
\hline Model & 12 & 2.191 & 2 & 0.334 & 1.096 \\
\hline
\end{tabular}

Table 8: Chi-square test $\left(\chi^{2}\right)$

Except the chi-square test, there are the following indicators of suitability models: RMSR (root mean square residual), GFI (goodness of fit index), IFI (incremental fit 
index), TLI index (Tucker and Lewis index), CFI (comparative fit index) and NFI (normed fit index). The results of these models are presented in Table 9.

\begin{tabular}{|l|c|c|c|c|c|c|}
\hline & RMSR & GFI & IFI & TLI & CFI & NFI \\
\hline Model & 0.002 & 0.996 & 0.980 & 0.859 & 0.999 & 0.922 \\
\hline
\end{tabular}

Table 9: Indicators of suitability models

The low value of RMSR indicates that the model is appropriate, just like most of the other indexes of suitability models with an approximate value of 0.9 or greater.

Results of confirmatory factor analysis were used in further analysis by comparing the standardized factor loadings in pairs to get the appropriate weights using eigenvectors. The method of eigenvectors is developed with the intention to help the decision-maker solve problems of multi-criteria decision making. In this sense, there are four criteria or parts of management control systems. Expert Choice was used because it is decision-making software that is based on multi-criteria decision making. Based on the obtained weights, the weighted average of the normalized values of indicators was calculated to get a single (aggregate or composite) indicator of management control systems. The value of a single (aggregate) indicator will show the level or degree of formalization of management control systems for each company on a scale from $0 \%$ to $100 \%$. Appropriate weights are shown in Figure 2.

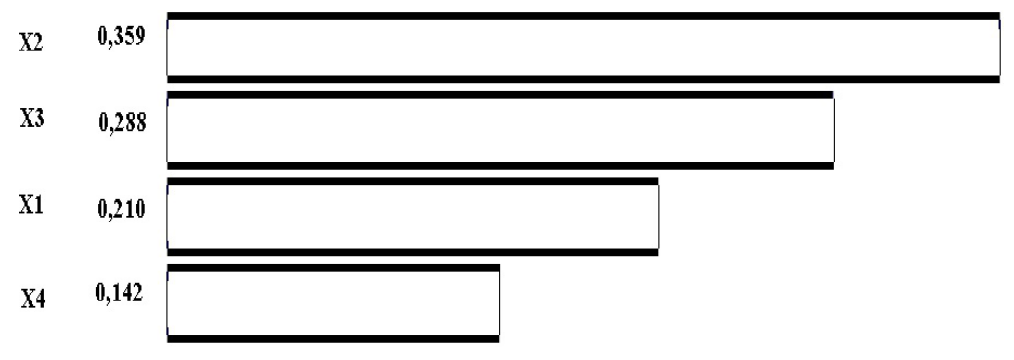

Figure 2: Appropriate weights for four parts of management control systems

Figure 2 shows the values of the weights, that is the measures of the relative importance of each control of management control systems. Administrative controls (X2) has the highest relative importance (35.9\%), the second by the relative importance are cybernetic controls (X3) with a value of $28.8 \%$, followed by the cultural controls (X1) with $21.0 \%$ and, finally, reward and compensation controls (X4) with a value of $14.2 \%$. The procedure of calculating the weights was used to form an aggregate, the composite indicators of management control systems according to the following formula:

$$
M C S_{i}=0.210 * X_{i, 1}+0.359 * X_{i, 2}+0.288 * X_{i, 3}+0.142 * X_{i, 4}
$$

The results of an aggregate indicator of MCS are presented in Table 10.

According to research results, companies in Croatia have more formalized MCS - more use of cybernetic controls (except non-financial measures), more use of administrative and cultural controls and more use of reward and compensation based 


\begin{tabular}{|l|c|}
\hline & MCS \\
\hline $\mathrm{N}$ & 124 \\
\hline Mean & 0.6564333 \\
\hline Std. deviation & 0.11499230 \\
\hline Minimum & 0.17851 \\
\hline Maximum & 0.84941 \\
\hline
\end{tabular}

Table 10: Formalization of $M C S$

on internal standards, objective criteria and short-term measures in regard to the less formalized MCS - less use of cybernetic (except non-financial measures), less use of administrative and cultural controls and more use of reward and compensation based on external standards, subjective criteria and long-term measures. Bearing the above in mind, the hypothesis is accepted as valid.

\section{Conclusion}

The first problem in undertaking MCS research is the definition of MCS because some research focuses on broad conceptions of what could be considered as MCS, but also some research focuses on single aspects of MCS. The lack of clarity and the inconsistencies in the definition of MCS have created a number of problems in MCS research in regard to the interpretation of research results. Prior research provides only fragmented evidence on the nature of the relationships between controls of MCS. In research of Auzair and Langfield-Smith [6], MCS was conceptualized in terms of five dimensions: action/results controls, formal/informal controls, tight/loose controls, restricted/flexible controls, and impersonal/interpersonal controls to form a composite measure of the degree of MCS bureaucracy. In their research MCS was defined as a multi-dimensional construct on a continuum from less bureaucratic to more bureaucratic.

This study was designed to empirically test the concept of MCS as a package of cybernetic, reward and compensation, administrative and cultural controls in Croatia. In this paper, the concept of MCS as a package of controls with related techniques was used for the purpose of guiding and motivating employees to accomplish organizational goals. This concept is based on research of Malmi and Brown [14] which suggests a new typology for research MCS as a package of controls. Results of this research indicated that companies in Croatia most frequently used more formalized MCS - more use of cybernetic controls (except non-financial measures), more use of administrative and cultural controls and more use of reward and compensation based on internal standards, objective criteria and short-term measures with respect to use of less formalized MCS - less use of cybernetic (except non-financial measures), less use of administrative and cultural controls and more use of reward and compensation based on external standards, subjective criteria and long-term measures.

This research makes the following contributions. Firstly, in this study MCS is conceptualized as a multi-dimensional construct on a continuum from less formalization to more formalization of MCS. A comprehensive measure of MCS consisting 
of four dimensions is developed to support this model. Secondly, while most prior research has focused on MCS in manufacturing firms, this study focuses on all companies in Croatia, regardless of their activity. The research is also subject to a number of limitations. Firstly, the model is tested using survey data and thus it is subject to the usual limitations associated with such data. Secondly, this research examines issues related to the definition and elements of MCS with no attempt to assess the meaning and measurement of influential factors and their impact on MCS. In spite of the potential limitations of the study, this is one of the few empirical studies conducted in the field of MCS in Croatia.

\section{References}

[1] Abernethy, M.A. and Chua, W. (1996). Field study of control system "redesign": the impact of institutional process on strategic choice. Contemporary Accounting Research, 13, 569-606.

[2] Albright, J. J. and Park H. M. (2009). Confirmatory Factor Analysis Using Amos, LISREL, Mplus, and SAS/STAT CALIS. Working Paper. The University Information Technology Services (UITS) Center for Statistical and Mathematical Computing. Indiana University. http://www.indiana.edu/ statmath/stat/all/cfa/index.html [Accessed on 7 October 2013].

[3] Al-Dahiyat, Mohammed Abdul Rahim (2003). Towards an effective design of Management control systems: a contingency approach. http://eprints.hud.ac.uk/5939/1/273719.pdf [Accessed on 2 June 2010].

[4] Alvesson, M. and Karreman, D. (2004). Interfaces of control. Technocratic and socioideological control in a global management consultancy firm. Accounting Organizations and Society, 29, 423-444.

[5] Anthony, R. N. (1965). Planning and Control Systems: A Framework for Analysis. Boston: Harvard University.

[6] Auzair, S. M. and Langfield-Smith, K. (2005). The effect of service process type, business strategy and life cycle stage on bureaucratic MCS in service organizations. Management Accounting Research, 16, 399-421.

[7] Bonner, S. and Sprinkle, G. (2002). The effects of monetary incentives on effort and task performance: theories, evidence, and a framework for research. Accounting Organizations and Society, 27, 303-345.

[8] Carenys, J. (2010). Management Control Systems: A Historical Perspective. International Bulletin of Business Administration, 7, 37-54.

[9] Chenhall, R. (2003). Management control systems design within its organizational context: findings from contingency-based research and directions for the future. Accounting Organizations and Society, 28, 127-168.

[10] Cunningham, G. M. (1992). Management control and accounting systems under a competitive strategy. Accounting, Auditing and Accountability Journal, 5, 85-102.

[11] Dropulić, I. and Pervan, I. (2013). Design of Budget Controls: A Study for Croatian Manufacturing Companies, Recent Researches in Applied Economics and Management Business Administration and Financial Management - Volume 1, Proceedings of the 5th International Conference on Applied Economics, Business and Development, Published by WSEAS Press, Greece, 284-289.

[12] Flamholtz, E., Das, T., and Tsui, A. (1985). Toward an integrative framework of organizational control. Accounting Organizations and Society, 10, 35-50. 
[13] Hoque, Z. (2004). A contingency model of the association between strategy, environmental uncertainty and performance measurement: impact on organizational performance. International Business Review, 13, 485-502.

[14] Malmi, T. and Brown, D. (2008). Management control systems as a package - Opportunities, challenges and research directions. Management Accounting Research, 19, 287-300.

[15] Merchant, K. and Van der Stede, W. (2007). Management control systems: performance measurement, evaluation and incentives. England: Pearson Education Limited.

[16] Otley, D. (1980). The contingency theory of management accounting: achievement and prognosis. Accounting, Organizations and Society, 5, 413-428.

[17] Ramljak, B. and Rogošić, A. (2012). Strategic management accounting practices in Croatia, The Journal of International Management Studies, 7, 93-100.

[18] Sandelin, M. (2008). Operation of management control practices as a package - A case study on control system variety in a growth firm context. Management Accounting Research, 19, 324-343.

[19] Saunders, M., Lewis, P., and Thornhill, A. (2009). Research methods for business students. England: Pearson Education Limited.

[20] The Official Gazette of the Republic of Croatia (2007). Accounting Act. http://narodne-novine.nn.hr/clanci/sluzbeni/329423.html [Accessed on 2 July 2013].

[21] The Official Gazette of the Republic of Croatia (2007). National Classification of Activities 2007 - NCA 2007

http://narodne-novine.nn.hr/clanci/sluzbeni/2007_06_58_1870.html

[Accessed on 2 July 2013]. 